\title{
Research and Practice of Teaching Reform of Organic Synthesis in Universities
}

\author{
Jinyu Sun, Baoping Zhai, Sanhu Zhao, Minggen Zhao* \\ Department of Chemistry, Xin Zhou Teachers University, Xin Zhou 034000, Shanxi, China. \\ Corresponding author:ZHAO Minggen, Tel.:0350-3339205 Fax:0350-3031845; \\ E-mail:zhao_minggen@aliyun.com
}

Fund Project: Sponsored by the Fund for Shanxi “1331 project” Key Subject Construction (No:JGZD201907)

Abstract: The teaching content of organic synthesis is rigorous and has high standards for students' knowledge application ability, thinking ability and learning ability. Therefore, how to promote the high-efficiency development of organic synthesis classroom teaching activities in colleges and universities has become a problem that needs to be studied by teachers. The author starts from the factors that hinder the development of organic synthesis classrooms in colleges and universities, and through an in-depth analysis of the actual teaching situation, finds a specific way to promote the smooth progress of the reform. Long-term development of career.

Keywords: Teaching reform; higher education; teaching methods; organic synthesis teaching

The accelerating reform of higher education has made obsolete teaching ideas and talent cultivation models no longer meet the current educational requirements, and colleges and universities need to be able to coordinate with the changing development plan of the era in order to successfully promote and cultivate the teaching reform Highlyqualified talents who can better meet the requirements of job development. Organic synthesis teaching has high requirements for students' learning ability, chemical literacy and inquiry ability, so it not only has new requirements for teachers' teaching ability, but also needs to be able to conduct classroom teaching activities in combination with the actual teaching under the guidance of emerging education concepts. Reform can promote the orderly development of teaching work on the basis of mobilizing the enthusiasm of students to participate in classroom knowledge learning, and lay the foundation for cultivating high-quality organic synthesis talents.

\section{Factors hindering the development of organic synthesis classrooms in colleges and universities}

\subsection{Teaching methods are backward}

The content of organic chemistry teaching covers a wide range. It requires students to have a solid grasp of knowledge such as functional groups, synthetic strategies, bases, synthetic reactions, organic substances, and synthetic reagents. It also needs to be able to engage in the development of photosensitive materials through the application of different chemical reactions. , Fine chemical industry, etc. Although multimedia technology is widely used in classroom teaching activities, teachers are still constrained by outdated teaching concepts, and the teaching methods used are backward, and they will focus on teaching theoretical knowledge, rarely mobilizing through the introduction of teaching cases. Student thinking. In addition, when teachers are conducting teaching activities, even if they introduce different teaching methods in order to innovate the teaching environment, they still mainly rely on their own unilateral teaching methods to teach knowledge, resulting in students not only failing to exert their subjective initiative in the

Copyright (C) 2020 Jinyu Sun et al.

doi: 10.18282/le.v9i5.1240

This is an open-access article distributed under the terms of the Creative Commons Attribution Non-Commercial License

(http://creativecommons.org/licenses/by-nc/4.0/), which permits unrestricted non-commercial use, distribution, and reproduction in any medium, provided the original work is properly cited. 
passive learning of knowledge, but also While inhibiting its individualized development, it seriously affects the smooth implementation of teaching reform.

\subsection{Poor extensibility of teaching content}

In order to ensure the effectiveness of teaching, many teachers will focus on the explanation of the teaching material when conducting the teaching work, and rarely expand the teaching content accordingly. Due to the rapid development of the chemical industry, backward teaching content can not only help students to understand the prospects of the industry, but the boring learning environment is also difficult to inspire students to participate in classroom knowledge. In addition, as a compulsory course for chemistry majors, organic synthesis not only has a very broad knowledge framework, but also requires a lot of knowledge content that students need to remember. When teachers are teaching, the lack of enrichment and extension of the teaching content makes it difficult for students to mobilize their enthusiasm when conducting learning activities. The complex knowledge system also seriously reduces their learning efficiency, which hinders the high quality of classroom teaching activities. Carry out.

\section{The concrete ways of the reform of organic synthesis classroom in colleges and universities}

\subsection{Innovative teaching methods}

Because many chemical reactions in organic synthesis are relatively abstract, teachers do not have the experimental conditions when conducting teaching activities. In order to ensure the high-quality development of classroom teaching activities, teachers need to be aware of the importance of innovative teaching methods under the guidance of a new educational perspective Sex, and change their teaching habits as a classroom teaching center, returning the subject status of the classroom to the students, so that they can ensure the effective improvement of learning efficiency under the adjustment of their subjective initiative. Therefore, teachers can introduce three-dimensional stereoscopic image technology into teaching activities, so that students can intuitively understand various chemical reactions and synthesis processes when learning classroom knowledge. In this way, not only can students' enthusiasm for learning be fully mobilized, but interesting learning methods also make it easier for students to extend their thinking consciousness to ensure the improvement of learning quality, and then achieve the purpose of promoting the smooth progress of teaching reform.

\subsection{Extend the teaching content}

In order to promote the smooth implementation of teaching reform, teachers need to combine the future development prospects of organic synthesis, and be able to enrich the content of the lectures in accordance with the actual situation, in order to promote the comprehensive development of students, so that they can grow to meet the requirements of organic synthesis professional Talent.

First of all, teachers need to adjust the lesson plan, not only need to focus on the mastery of students' professional knowledge, but also need to increase the experimental class hours, so that students can participate in experimental activities, both to improve their own hands-on ability and have a better understanding of knowledge During the process, to ensure the rapid improvement of professional skills.

Secondly, teachers need to pay attention to guiding students to learn new knowledge before they can inquire into their chemical reactions and synthesis principles, such as explaining functional group protection, organic reagents, organic synthesis reactions and reverse synthesis, which can help students to understand the context of knowledge. The carding guides them to ensure the rapid rise of learning efficiency in the process of continuously improving thinking consciousness and synthetic thinking.

Finally, teachers also need to be able to keep up with the latest achievements in organic synthesis when teaching, and introduce new reactions and new dynamics into teaching activities, so that students can feel the joy of learning organic synthesis knowledge while enriching their knowledge. Furthermore, it promotes the smooth completion of classroom education reform while enhancing its learning initiative. 


\section{Conclusion}

Continuous changes in society have made higher demands on highly synthetic organic synthetic talents in different fields. Therefore, teachers in colleges and universities need to closely integrate the current actual teaching situation when conducting teaching activities, and make targeted preparations to ensure that the teaching work is smooth The content of the teaching reform carried out can make the students cultivated not only have higher professional skills, but also meet the actual requirements of the post. This will not only enable students to achieve a more comprehensive development, but also promote the rapid implementation of higher education sports reform in my country, and enable the long-term development of organic synthetic education.

\section{References}

1. Wu Shaoyan, Zhu Yuanyuan, Li Qin. Application of green chemistry concept in fine organic synthetic chemistry experiment teaching of chemical engineering specialty[J]. Guangdong Chemical Industry, 2018, 45(24): 59-60.

2. Fu Renzhong, Yang Yang, Zeng Xiaojun, Yuan Rongxin, Soumyajit Roy. Bilingual teaching practice and exploration of "Basics of Organic Synthesis" in local universities[J]. Guangzhou Chemical Industry, 2016, 44(10): 233-234.

3. Li Haihua. The reform and exploration of the course "Principles of Fine Organic Synthesis" under the combination of production, teaching and research [J]. Guangdong Chemical Industry, 2014, 41(06): 196+188. 